\title{
Variáveis Descritivas do Altruísmo na Análise do Comportamento*
}

\author{
Renan Kois Guimarães ${ }^{1, * *}$ (1) \& Carolina Laurenti ${ }^{2, * *}$ (] \\ ${ }^{1}$ Universidade Estadual de Londrina, Londrina, PR, Brasil \\ ${ }^{2}$ Universidade Estadual de Maringá, Maringá, PR, Brasil
}

\begin{abstract}
RESUMO - Esta pesquisa objetivou sistematizar as variáveis descritivas citadas na literatura analítico-comportamental sobre o altruísmo. Foram realizadas buscas em bases de dados e periódicos brasileiros especializados em Análise do Comportamento. Descritores relacionados à Análise do Comportamento foram combinados com as palavras altruísmo e altruísta, resultando em 19 artigos. As análises indicaram que o altruísmo foi abordado como uma classe de comportamentos com topografias variadas, desde simpáticas até agressivas, que ocorre sob o controle antecedente de regras e autorregras, e de operações estabelecedoras, como a empatia. Como consequências que podem manter o comportamento altruísta, foram identificadas consequências imediatas (produção de reforçadores positivos, remoção de eventos aversivos), e também consequências reforçadoras positivas atrasadas, que caracterizariam o altruísmo como um padrão comportamental molar e autocontrolado.
\end{abstract}

PALAVRAS-CHAVES: altruísmo, comportamento altruísta, comportamento molar, comportamento social

\section{Descriptive Variables of Altruism in Behavior Analysis}

\begin{abstract}
This research aimed to systematize the descriptive variables cited in the behavior-analytic literature about altruism. Searches were performed in databases and Brazilian journals specialized in Behavior Analysis. Descriptors related to Behavior Analysis were combined with the words altruism and altruistic, resulting in 19 articles. The analyses indicated that altruism was approached as a class of behaviors with varied topographies, from sympathetic to aggressive ones, occurring under the antecedent control of rules and self-rules, and of establishing operations such as empathy. As consequences that can maintain altruistic behavior, immediate consequences were identified (production of positive reinforcers, removal of aversive events), and also delayed positive reinforcing consequences, which would characterize altruism as a molar and self-controlled behavioral pattern.
\end{abstract}

KEYWORDS: altruism, altruistic behavior, molar behavior, social behavior

O comportamento social foi definido por Skinner (1953/1965) como o comportamento de pelo menos duas pessoas, sendo uma em relação à outra ou conjuntamente em relação ao ambiente. Sampaio e Andery (2010) destacam que o comportamento social se estabelece na medida em que as contingências para o comportamento de um organismo são produzidas pelo comportamento de outro(s) organismo(s): "consideramos comportamento social, portanto, qualquer contingência tríplice cujas consequências são mediadas pelo comportamento operante de outro(s) indivíduo(s)" (p. 184).

Além das contribuições de Skinner (1953/1965, 1971/2002, 1978, 1987) para a discussão do comportamento social, Holpert
(2004) relata um aumento, a partir de 1990, na produção de conhecimento analítico-comportamental sobre o tema. Dentre as diversas propostas de pesquisa em comportamento social, alguns tópicos se destacam: habilidades sociais (Murta, 2005), metacontingências e macrocontingências (Martins \& Leite, 2016), comportamento verbal (Wechsler \& Amaral, 2009), comportamento governado por regras (Maio \& Silva, 2015) e cooperação (Fidelis \& Faleiros, 2017). Guerin (2009) acrescenta que fenômenos tradicionalmente investigados por psicólogos sociais (e.g., cooperação, comparação social, comportamento de ajuda, processos de interdependência) passaram a despertar o interesse de analistas do comportamento.

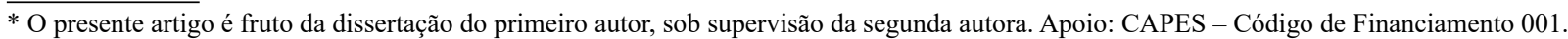

**E-mail: renankois@gmail.com e claurenti@uem.br

- Submetido: 08/01/2020; Revisado: 26/05/2020; Aceito: 30/06/2020.
} 
Um tipo de comportamento social que também é explorado pela Análise do Comportamento é o altruísmo. Entretanto, diferentemente de outros temas sociais investigados pela área, o altruísmo impõe, a princípio, algumas dificuldades suplementares de estudo. A principal dificuldade refere-se à concepção tradicional de altruísmo, que o entende como um comportamento que não visa vantagens e/ou produz algum prejuízo para quem se comporta altruisticamente. Parafraseando essa concepção tradicional em termos comportamentais, o comportamento altruísta, de um lado, não produziria reforçadores positivos e, de outro, geraria consequências aversivas para quem se comporta em benefício de outrem (Zin, 2017).

Essa concepção tradicional de altruísmo é incompatível com os princípios do condicionamento operante, dentre os quais se explica a manutenção ou aumento da frequência de um dado tipo de comportamento com base nas consequências reforçadoras por ele produzidas (Skinner, 1953/1965). Dessa forma, compreender o altruísmo como um fenômeno comportamental implica aceitar que ele produz consequências reforçadoras, não só para o(s) outro(s), mas também para quem se comporta (Zin, 2017).

Contudo, a aceitação do altruísmo como um comportamento reforçado não soluciona a questão, apenas transfere o problema para como definir e explicar o comportamento altruísta de modo coerente com os princípios da Análise do Comportamento sem descaracterizá-lo. Na literatura da área, é possível encontrar diferentes noções de altruísmo. Há a defesa de que o altruísmo é um padrão comportamental molar e autocontrolado (e.g., Locey \& Rachlin, 2013), a discussão da possibilidade de um altruísmo desinteressado (e.g., Melo, 2004), a noção de altruísmo como um comportamento moral (e.g., Peláez, 2001) e o entendimento do altruísmo como uma forma de cooperação (e.g., Chater et al., 2008). Ademais, diversas estratégias investigativas foram empregadas para estudar o fenômeno (i.e., pesquisas teóricas, básicas e aplicadas), além de modelos experimentais distintos, como o jogo do Dilema do Prisioneiro e o Jogo da Partilha (e.g., Fantino et al., 2007).

Existe, então, uma diversidade de conceptualizações e estratégias metodológicas utilizadas no estudo do altruísmo pela Análise do Comportamento, o que sugere um interesse crescente da área por esse fenômeno (ver Guimarães \& Laurenti, 2019). Diante dessa diversidade, uma revisão integrativa da literatura sobre o altruísmo pode conferir aos leitores um panorama das discussões e pesquisas sobre o tema na Análise do Comportamento e, assim, fomentar novas investigações na área que levem em consideração as diferentes perspectivas conceituais e metodológicas. Com isso, o objetivo deste artigo é sistematizar as explicações do altruísmo oferecidas pela Análise do Comportamento, por meio de uma descrição das principais variáveis mencionadas nos estudos analítico-comportamentais deste fenômeno.

\section{MÉTODO}

Foi realizada uma revisão integrativa de literatura, cujas fontes foram artigos buscados em três bases de dados que indexam os principais periódicos de Psicologia: IndexPsi, Scielo e PsycINFO. Também foram realizadas buscas nos três periódicos analítico-comportamentais brasileiros: Revista Brasileira de Análise do Comportamento, Revista Brasileira de Terapia Comportamental e Cognitiva e Revista Perspectivas em Análise do Comportamento.

\section{Primeira Etapa: Delimitação dos Descritores de Busca}

Foram delimitadas 30 combinações de descritores em português e inglês. Termos relacionados ao altruísmo (i.e., altruísmo, altruista, altruism e altruistic) foram combinados com palavras referentes à Análise do Comportamento (i.e., Análise do Comportamento, comportamentalismo, behaviorismo, seleção por consequências, condicionamento operante, comportamento operante, reforçamento, reforço, Behavior Analysis, behaviorism, selection by consequences, operant conditioning, operant behavior, reinforcement $e$ reinforcing).

\section{Segunda Etapa: Definição dos Critérios de Inclusão e Exclusão}

Artigos em língua portuguesa e inglesa, disponíveis online, na íntegra e gratuitamente, foram selecionados independentemente da data de publicação. Foram incluídas as fontes que apresentavam o mínimo de duas ocorrências do termo altruísmo e/ou altruista ao longo de todo o artigo, considerando título, resumo, palavras-chave e/ou corpo do texto, sendo que ao menos uma das ocorrências deveria estar nesse último campo, e que examinavam o tema com um viés analítico-comportamental. Foram excluídos os artigos que discutiam o altruísmo com base em outras teorias psicológicas; que tratavam do altruísmo no âmbito analítico-comportamental de maneira periférica, citando-o apenas como um exemplo de uma discussão mais ampla; que utilizaram os termos analíticocomportamentais de maneira coloquial (e.g., reforçar como sinônimo de "corroborar uma ideia"); e publicações que não apresentavam uma estrutura convencional de artigo, com seções de introdução, método, resultados, discussão e conclusão. 


\section{Terceira Etapa: Busca das Publicações}

As buscas foram realizadas nas bases de dados entre 3 e 12 de maio de 2018, e nas revistas nacionais de Análise do Comportamento, no dia 18 de março de 2019. Todas as buscas foram refeitas no dia 20 de abril de 2020 para atualização. Os descritores poderiam aparecer em qualquer campo e foram combinados com o vocábulo and. Não houve restrição de datas e a busca contemplou apenas artigos. Após as buscas, foi feito o download do material encontrado. Já nas revistas brasileiras especializadas em Análise do Comportamento, o procedimento se deu pelo download de todos os volumes e números dos periódicos em $P D F$.

\section{Quarta Etapa: Seleção das Publicações}

Após o download da bibliografia encontrada, foram excluídas as repetições. Os artigos restantes foram selecionados para leitura preliminar ${ }^{1}$. $\mathrm{O}$ recurso de busca no interior do documento (e.g., Ctrl+F) foi utilizado como ferramenta de seleção, buscando-se pelos descritores selecionados na primeira etapa. O parágrafo que continha a palavra foi lido e, quando necessário, o parágrafo anterior e/ou posterior também era $(\mathrm{m})$ consultado(s). Nos artigos em que a busca no interior do documento não funcionou, o texto foi lido na íntegra. Os artigos que satisfizeram os critérios de exclusão foram eliminados. Nos periódicos especializados em Análise do Comportamento também foi feita a busca no interior do documento, utilizando-se apenas o radical altruís, uma vez que os artigos já estavam de acordo com o viés analítico-comportamental.

\section{Quinta Etapa: Leitura e Sistematização das Fontes}

Esta etapa consistiu na organização sistemática dos artigos selecionados. Para tanto, três tabelas foram construídas (tabelas de pesquisas básicas, aplicadas e teóricas), com o objetivo de auxiliar na compreensão do artigo. As tabelas de pesquisas básicas e aplicadas requisitavam o objetivo, os sujeitos/ participantes, o procedimento, as variáveis manipuladas, as definições/explicações do altruísmo. A tabela de pesquisas teóricas solicitava as definições/explicações do conceito e as principais teses tradicionais, críticas e teses alternativas, conforme caracterizadas por Lopes e Laurenti (2016).

\section{Sexta Etapa:Análise de Dados}

Esta etapa buscou construir uma análise interpretativa da bibliografia selecionada, tendo como apoio as informações sistematizadas nas tabelas. As variáveis envolvidas no estudo do comportamento altruísta também foram examinadas, buscando uma descrição das contingências implicadas nesse comportamento. A partir dessa análise, foram buscadas semelhanças e dessemelhanças entre as definições e explicações do altruísmo.

\section{RESULTADOS E DISCUSSÃO}

\section{Artigos Selecionados}

As buscas realizadas resultaram em 215 artigos, mas nenhum deles foi encontrado nas bases de dados nacionais (IndexPsi e Scielo). Do material encontrado, 201 artigos foram identificados pela pesquisa na base de dados internacional (PsycINFO) e 14 artigos foram encontrados nas revistas nacionais especializadas. Desse total, 47 artigos foram excluídos por não estarem acessíveis online, na íntegra e gratuitamente. Dentre os 168 artigos recuperados, outros 50 foram eliminados por repetição. Assim, 118 artigos foram pré-selecionados para leitura. Dentre esses artigos, 22 foram excluídos por não terem cumprido os seguintes critérios para elegibilidade: 1 artigo foi excluído por não apresentar introdução, resultados ou discussão do tema, caracterizandose como um resumo do método utilizado no estudo (e.g., Israely \& Guttmann, 1983); outros por apresentarem os termos referentes ao altruísmo (i.e., altruísmo, altruísta, altruism ou altruistic) apenas no título (1 artigo), no resumo

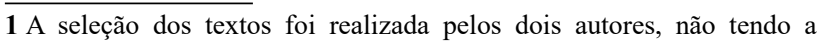
participação de um avaliador externo.
(2 artigos), nas referências bibliográficas (2 artigos) ou nas palavras-chave (4 artigos); 4 por não apresentarem esses termos; e 8 por usarem termos comportamentais (i.e., reforço, reforçamento, reinforcement e reinforcing) exclusivamente no sentido coloquial, isto é, como sinônimos de corroborar e/ou confirmar (e.g., "reforçar o status quo", "reforçar uma ideia").

Outros 30 artigos foram excluídos por tratarem perifericamente os termos relacionados ao altruísmo. Esses artigos tinham como foco o comportamento de partilha, o treinamento de habilidade de cuidado ou a doação de sangue, utilizando os termos referentes ao altruísmo de forma genérica para denominar a classe de respostas a que esses comportamentos específicos pertenceriam (e.g., Ferrari et al., 1985). Os artigos que utilizaram os termos relacionados ao altruísmo apenas em citações diretas também foram excluídos por discutirem o tema perifericamente (e.g., Abib, 2016), assim como outros artigos que apresentaram os termos relacionados ao altruísmo como parte do método empregado em uma revisão de literatura, mas o altruísmo não era o foco do estudo (e.g., Fidelis \& Faleiros, 2017). Um total de 47 artigos foi excluído por apresentar explicações antitéticas à Análise do Comportamento, como explicações 
que recorriam a processos mediacionais (e.g., cognitivos, mentais, cerebrais, neuroquímicos, representações internas) para definir e explicar o altruísmo (e.g., Cialdini et al., 1981). Ao final, 19 artigos foram selecionados para análise, sendo 7 pesquisas teóricas, 10 básicas e 2 aplicadas.

\section{Análise Descritiva do Comportamento Altruísta}

A partir da análise dos artigos, foram identificadas as principais variáveis citadas nos estudos analíticocomportamentais para explicar o altruísmo. À vista disso, este tópico apresentará primeiramente uma breve descrição das variáveis filogenéticas e culturais exploradas pelos artigos selecionados. Posteriormente, uma descrição mais detalhada das variáveis ontogenéticas será realizada, levando em conta as topografias, os antecedentes e as consequências envolvidas no comportamento altruísta.

Assim como outros comportamentos sociais complexos, o estudo do altruísmo deve considerar os diversos níveis de variação e seleção do comportamento (i.e., filogenético, ontogenético e cultural), conforme ressaltado por Rachlin e Locey (2011). Alguns dos textos examinados discutiram a importância do nível filogenético de seleção do altruísmo (Locey \& Rachlin, 2013; Rachlin, 2012, 2019; Zin et al., 2015). De uma perspectiva biológica, o comportamento altruísta reduziria a capacidade de um organismo sobreviver em prol da sobrevivência de outrem, favorecendo o outro à custa de seu benefício próprio (Locey \& Rachlin, 2013; Zin et al., 2015).

Ainda que essa concepção pareça contraditória com a importância da sobrevivência na teoria da seleção natural, Locey e Rachlin (2013) e Rachlin $(2012,2019)$ defendem a possibilidade de um altruísmo no âmbito filogenético, tomando como base a acepção de evolução voltada ao gene. Essa concepção defende que o material genético é o veículo da evolução e não o organismo em si: "os organismos podem sacrificar sua própria sobrevivência [fitness] em relação aos parentes próximos, preservando, assim, a sobrevivência dos genes que compartilham" (Locey \& Rachlin, 2013, p. 245)².

Como resultado dessa perspectiva filogenética, os autores consideram a existência de uma herança biológica no comportamento altruísta, mas não reduzem o fenômeno a esse nível. Nas palavras de Rachlin e Locey (2011): "é claro que o comportamento altruísta, como todo comportamento aprendido [ênfase adicionada], depende fortemente da herança biológica" (p. 28). Entretanto, a herança biológica não ajuda a entender como uma pessoa pode aprender a ser altruísta (Rachlin, 2019).

Ao compreender o altruísmo como um fenômeno complexo e passível de aprendizagem, a importância da

2 Do ponto de vista evolutivo, existem diversos debates sobre o altruísmo, não havendo consenso entre os biólogos a respeito de qual é a unidade de seleção filogenética (Dawkins, 1989) e nem sobre a necessidade de parentalidade (e.g., De Waal, 2009/2010; Hamilton, 1963). seleção cultural no estabelecimento de comportamentos altruístas foi levada em consideração pelos textos examinados. Uma variável descritiva levantada referiu-se à importância dos reforçadores sociais generalizados (e.g., "obrigado" e "por favor") na construção e manutenção de comportamentos altruístas (Killeen \& Snowberry, 1982). Segundo os autores, comunidades verbais que estabelecem práticas que utilizam esse tipo de reforçador aumentam a probabilidade de o comportamento altruísta ser emitido. $\mathrm{O}$ altruísmo também foi entendido como um comportamento moral que é modelado por uma comunidade verbal (Peláez, 2001). De acordo com a autora, como qualquer comportamento moral, o altruísmo deve ser intencional ou deliberado, perpassado pelas ideias de "certo" ou "bom" e sem consequências benéficas e óbvias para quem se comporta. Tendo em vista que as práticas contemporâneas estão baseadas no lucro, no comércio etc., tem sido investigada a necessidade de incentivos institucionais (e.g., a retirada ou isenção de taxas e tarifas relacionadas a comportamentos que beneficiem outrem; campanhas de doação) e mudanças políticas para a promoção de comportamentos altruístas (Goldstein et al., 1978). Além disso, também tem sido indicado que a ocidentalização de um país pode alterar as práticas culturais altruístas para práticas egoístas, por incentivarem comportamentos relacionados à competição, ao lucro e ao benefício próprio (Bethlehem, 1973).

As variáveis descritivas pertinentes ao nível ontogenético foram as mais discutidas nos estudos selecionados. Partindo da noção de contingência de reforçamento exposta por Skinner (1953/1965) e entendendo que esse é um conceito fundamental na explicação comportamental, este artigo apresentará as principais contribuições dos textos examinados por meio da noção de contingência de três termos. A análise subsequente explorará, então, as ações, situações antecedentes e consequentes mencionadas na explicação do comportamento altruísta.

Ação. Os artigos analisados investigaram diversas topografias do comportamento altruísta. Dentre elas, a doação destacou-se como uma das mais mencionadas. Weiner (1977) discutiu a ação de compartilhar recursos ou a doação de moedas para outro jogador, Grusec e Redler (1980) tiveram como foco de estudo a doação de parte dos lucros de uma criança para outra, e Parish (1977) examinou a doação de chocolate para outros colegas. No estudo de Watson (1996), a topografia investigada foi a de manter as paredes de banheiros de uma universidade sem pichações. Rachlin e Locey (2011) descreveram outra topografia do comportamento altruísta: "viajantes: cada um vai mais rápido se dirigir, mas se todos dirigirem, cada um vai mais devagar do que se todos pegassem ônibus" (p. 26). Outro exemplo descrito por Rachlin $(2012,2019)$ foi o de um jogador que renuncia à individualidade (e.g., desistindo de fazer mais pontos ou de ser artilheiro) e joga em função de um resultado coletivo maior, conquistando prêmios coletivos (e.g., o campeonato). 
Peláez (2001) defendeu que o altruísmo não se dá apenas por meio de topografias de simpatia (i.e., que envolvem um menor grau de aversividade), mas também em topografias mais agressivas (i.e., que envolvem um maior grau de aversividade). Essas últimas podem ser vistas, por exemplo, em situações em que o uso de força é necessário para impedir que um indivíduo seja ainda mais prejudicado se não for contido (e.g., comportamentos autolesivos). Nesses casos, a ação altruísta pode chegar a níveis extremos, variando desde dar a vida por uma causa ou pessoa, até tirar a vida de alguém, como no caso da eutanásia:

Ela [ação altruísta] pode aparecer como agressão em direção a um atacante, como quando alguém luta para defender os direitos do outro. Ela também pode aparecer como comportamento agressivo em direção à vítima - como no caso da eutanásia. Outras vezes, a empatia pode desencadear a autodepreciação ou a retirada de uma dada situação, como quando a pessoa que está prestes a receber comida em uma prisão ou campo de concentração se abstém dela por causa de outra pessoa faminta ou doente. (Peláez, 2001, p. 12)

Além das diversas topografias descritas, o custo de resposta parece ser um fator importante que está relacionado à definição da ação altruísta. Goldstein et al. (1978) demonstraram que o aumento do custo de resposta pode diminuir a probabilidade de o comportamento altruísta ser emitido. Nessa pesquisa, o custo de resposta estava relacionado à perda de reforçadores arbitrários para quem se comportava altruisticamente (i.e., o pagamento da taxa para anúncio de objetos encontrados). Nos exemplos citados por Rachlin e Locey (2011), o aumento do custo de resposta para os viajantes estaria relacionado ao tempo de viagem (i.e., perderiam reforçadores, pois chegariam ao destino mais tardiamente) e ao deslocamento até à rodoviária para pegar o ônibus, em vez de sair da própria casa (i.e., aumento do esforço físico). A redução do custo de resposta poderia, então, ser útil para o favorecimento de comportamentos altruístas. Ainda assim, recorrendo à definição de Weiner (1977), comportamentos altruístas, com um alto custo de resposta, poderiam ser considerados mais altruístas.

Em suma, mesmo que possa ser emitido com diferentes topografias, o comportamento altruísta pode ser definido como tal dependendo da função que apresenta, e essa função é estabelecida na relação entre a ação e as situações antecedentes e consequentes.

Situação antecedente. Das situações antecedentes descritas pelos artigos analisados, a operação estabelecedora foi citada como uma importante variável de explicação do comportamento altruísta (Belisle et al., 2019). De acordo com Peláez (2001), a empatia, entendida como uma resposta emocional produzida por respostas emocionais de outra pessoa, poderia ter "várias funções para a motivação do comportamento humano: pode fornecer a base para o cuidado da prole, a fidelidade conjugal, a coesão grupal e a conformidade moral, bem como para os comportamentos de ajuda, partilha, cooperação e altruísmo" (p. 13). A autora ressalta, ainda, que "apresentar um comportamento altruísta, um comportamento de autossacrifício, ou ajudar na presença do sofrimento de outra pessoa muitas vezes é facilitado pela empatia [ênfase adicionada], funcionando como uma operação estabelecedora" (p. 12) ${ }^{3}$.

Buscando amparo na literatura analítico-comportamental, Michael (2000) e Laraway et al. (2003) expuseram que as operações estabelecedoras, comumente investigadas no contexto da motivação, apresentam dois efeitos: (i) alteram a efetividade reforçadora da consequência de um comportamento (i.e., efeito estabelecedor do reforço); e (ii) alteram a frequência do comportamento reforçado por aquela consequência (i.e., efeito evocador). Para definir a empatia como uma operação estabelecedora, seria necessário, então, o cumprimento desses aspectos.

$\mathrm{O}$ efeito estabelecedor do reforço conferido à empatia pode ser visto na defesa de Peláez (2001): "sentir empatia, que funciona como sentir fome ou sentir sede, ou sentir-se emotivo pode aumentar o valor dos reforços associados ao comportamento" (p. 12). Por exemplo, a empatia pode aumentar o valor reforçador da eliminação do sofrimento alheio. Já em relação ao efeito evocativo, a empatia também poderia fortalecer o controle exercido por eventos antecedentes (e.g., a empatia pode estar envolvida em uma maior sensibilidade ao sofrimento de outrem) e, consequentemente, a probabilidade de um indivíduo se comportar altruisticamente seria aumentada.

Outra variável de destaque no âmbito das situações antecedentes foi a regra. Watson (1996), por exemplo, investigou se a explicitação de uma regra interfere no comportamento altruísta. Nessa pesquisa, a regra "se o banheiro não for pichado, dinheiro será doado para uma instituição de caridade" (i.e., situação antecedente) descrevia uma contingência altruísta, uma vez que evidenciava consequências benéficas apenas para outrem. A exposição dos indivíduos a essa regra aumentou a probabilidade de emissão de comportamentos altruístas.

Além disso, também foram mencionadas situações em que autorregras consistiam em uma variável relevante para a emissão do comportamento altruísta:

O comportamento governado por regras pode ser capaz de explicar as condições sob as quais os indivíduos se voluntariam quando nenhuma contingência de ação direta é aparente. Por exemplo, um indivíduo pode gerar a regra implícita: "se eu me voluntariar, sou uma boa pessoa [ênfase adicionada]". (Brayko et al., 2016, p. 87)

A autorregra também foi explorada como autoimagem (e.g., Rachlin \& Locey, 2011). Na literatura analítico-

3 A concepção de empatia como uma operação estabelecedora não é consensual, visto que a empatia também já foi abordada no campo analítico-comportamental como um comportamento a ser ensinado (Del Prette \& Del Prette, 2011, 2017; Vettorazzi et al., 2005). 
comportamental, o conceito de autoimagem parece ter uma relação direta com a autoconsciência, entendida como a auto-observação e a autodescrição geradas por questionamentos e contingências de reforçamento e punição estabelecidas pela comunidade verbal em que um indivíduo está inserido (De Rose, 1982; Skinner, 1953/1965). A comunidade verbal não apenas leva o indivíduo a descrever seu próprio comportamento e condições corporais correlatas, mas também a valorar essa descrição por meio da classificação de comportamentos (i.e., controle ético) (Skinner, 1953/1965).

No altruísmo, a comunidade verbal classifica tanto o comportamento quanto o indivíduo como bondoso, benevolente ou altruísta, por exemplo. No âmbito desse controle ético, a pessoa não só descreve seu comportamento como altruísta, mas passa a se sentir e a se perceber como alguém altruísta. De acordo com Rachlin e Locey (2011), a autoimagem altruísta pode funcionar também como uma autorregra na medida em que descreve "se eu sou altruísta, então devo me comportar como tal". Assim, uma autoimagem altruísta poderia ser uma situação antecedente para a emissão de comportamentos altruístas.

Embora os textos analisados tenham enfatizado que descrições verbais de contingências altruístas, na forma de regras e autorregras (e.g., autoimagem), podem aumentar a probabilidade de emissão do comportamento altruísta, o papel das contingências de reforçamento na modelagem e manutenção desse comportamento também deve ser ressaltado.

Consequências. A maior diversidade de variáveis invocadas no estudo do altruísmo foi identificada no campo das consequências. Alguns autores defenderam (i) que a eliminação ou o adiamento de eventos aversivos pode manter o comportamento altruísta (e.g., Goldstein et al., 1978; Peláez, 2001; Zin et al., 2015), enquanto outros argumentaram em favor da (ii) possibilidade de manutenção do comportamento altruísta por reforçadores positivos (e.g., Brayko et al., 2016; Chater et al., 2008; Grusec \& Redler, 1980; Peláez, 2001; Rachlin, 2012; Weiner, 1977; Zin et al., 2015).

A possibilidade de o comportamento altruísta ser mantido por reforçamento negativo foi descrita por Goldstein et al. (1978): "o altruísmo pode estar baseado simplesmente na remoção da punição” (p. 466). Um exemplo pode ser delineado a partir dessa concepção: um indivíduo que doa agasalhos e cobertores para um abrigo poderia estar se comportando com a função de remover eventos aversivos antecedentes (e.g., ser identificado por sua comunidade verbal como uma pessoa mesquinha), caracterizando esse comportamento como fuga ou esquiva da desaprovação e rejeição social (Peláez, 2001). Além disso, como apontado por Zin et al. (2015), esse comportamento poderia ter a função de fuga/esquiva até mesmo da própria condição aversiva das pessoas do abrigo (e.g., as pessoas passarem frio).

Não obstante a possibilidade de o comportamento altruísta ser reforçado negativamente, as consequências reforçadoras positivas foram as mais exploradas. Peláez (2001) também discutiu a possibilidade de reforçadores positivos arbitrários (e.g., aprovação, aceitação, elogio, afeto) manterem o altruísmo. Outros reforçadores positivos envolvidos no comportamento altruísta foram descritos por Chater et al. (2008):

Muito altruísmo aparente pode ser explicado pela observação da existência de beneficios ocultos [ênfase adicionada]. Por exemplo, pode haver vantagens reprodutivas para a cooperação, se estivermos interagindo com parentes (Hamilton, 1964); pode haver benefícios ocultos a longo prazo, se nossa gentileza puder um dia ser retribuída (Axelrod, 1984; Axelrod \& Hamilton, 1981; Nowak \& Sigmund, 1989); podemos ser influenciados pela aprovação social, se estamos sendo observados pelos pares (Satow, 1975; Wedekind \& Braithwaite, 2002) e influenciados por fatores situacionais sociais, como o número de espectadores (Latane \& Darley, 1969). (p. 403)

Defender a existência de consequências reforçadoras ocultas é argumentar que elas podem não ser perceptíveis para quem está observando, mas não significa que elas não estejam presentes: "comportamentos paradoxais incluem aqueles como autossacrifício, martírio e altruísmo, em que parece não existir contingências óbvias e diretas [ênfase adicionada] controlando o comportamento moral. Na verdade, as consequências são bastante óbvias para quem se comporta" (Peláez, 2001, p. 9). Além de não ser necessário que sejam conspícuas, essas consequências não precisam ser imediatas. Nas palavras de Weiner (1977), “eventos históricos poderiam manter o doar sem o receber por longos períodos de tempo. Histórias de reforçamento comumente induzem respostas humanas estendidas na ausência de reforço durante a extinção" (p. 523).

Outro aspecto relacionado às consequências foi o foco no que está sendo reforçado. Grusec e Redler (1980) realizaram um procedimento que averiguou se a "atribuição de caráter" (e.g., "você é uma boa pessoa", "você é gentil") era mais efetiva do que o uso de reforçadores sociais generalizados (e.g., "parabéns", "muito bem") na manutenção e generalização de comportamentos altruístas. Por meio dos resultados obtidos, concluiu-se que a "atribuição de caráter" é mais efetiva, pois promove uma "autoimagem positiva", fazendo com que o comportamento altruísta seja mais generalizado e se mantenha por mais tempo. Trata-se de mais um exemplo que ilustra a autoimagem como uma variável importante a ser considerada na emissão de comportamentos altruístas. 


\section{O Altruísmo como um Comportamento Molar}

Os estudos sobre altruísmo têm se amparado, sobretudo, na perspectiva comportamental defendida por Rachlin. $\mathrm{O}$ autor foi utilizado como referência para embasar as discussões do altruísmo por 11 artigos (58\%), sendo que ele mesmo era autor de 5 deles (i.e., quase metade dos textos que tinham o autor como base para a discussão apresentaram autorreferência). Embora nem todos os artigos analisados tenham utilizado a acepção de altruísmo defendida por Rachlin, ela parece exercer grande impacto nas discussões sobre altruísmo no campo analítico-comportamental. Por essa razão, este tópico buscará descrever como o altruísmo pode ser entendido a partir de uma perspectiva molar de comportamento.

A concepção molar de altruísmo entende que "toda ação altruísta deriva do autocontrole" (Rachlin \& Locey, 2011, p. 29), sendo que o autocontrole é entendido como uma escolha entre consequência(s) imediata(s) e atrasada(s) (Rachlin, 1974). De acordo com o autor, em uma situação de escolha entre um reforçador de menor magnitude imediato e um reforçador de maior magnitude atrasado, o indivíduo demonstra autocontrole ao escolher a segunda opção. No caso do altruísmo, a escolha autocontrolada parece envolver também o enfrentamento de eventos aversivos imediatos. De acordo com Rachlin e Locey, a compreensão do comportamento altruísta como autocontrole tem, então, dois resultados significativos. Primeiramente, facilita a aceitação do altruísmo como um comportamento possível de ser estudado pela Análise do Comportamento, uma vez que o autocontrole já é um tema consolidado na área. Em segundo lugar, essa acepção busca resolver o problema relacionado à produção de reforçadores pelo comportamento altruísta:

Do ponto de vista comportamental, a dificuldade de explicar o comportamento altruísta não é intrinsecamente maior (ou menor) do que a dificuldade em explicar o autocontrole nas instâncias da vida cotidiana de ambivalência complexa. Não é contraditório para um comportamentalista dizer que o altruísmo é reforçado desde que o reforçador seja entendido como atuando não apenas naquela ação, mas no padrão do qual a ação faz parte. (Rachlin \& Locey, 2011; p. 32)

Nesse caso, as consequências mantenedoras do altruísmo são reforçadores atrasados que atuam no padrão comportamental altruísta. Como tal, esse padrão precisa ser construído (Locey \& Rachlin, 2013). Essa construção se dá por meio da emissão de diversas ações altruístas. Contudo, apenas a emissão dessas ações não é suficiente para classificar o altruísmo como um padrão, pois é necessário que essas ações sejam distendidas no tempo. Como exemplo, um indivíduo que participou de apenas uma ação social em prol de outrem não será classificado como alguém com um padrão de comportamento altruísta. Por outro lado, se o engajamento em ações sociais e outras ações altruístas forem frequentes no decorrer da vida desse indivíduo, esses comportamentos poderiam estar compondo um padrão comportamental altruísta. Além disso, essa concepção defende que há uma diferença qualitativa entre as consequências reforçadoras atrasadas de um padrão comportamental e as consequências aversivas imediatas de uma ação isolada:

... o todo é maior que a soma de suas partes; ... combinações de coisas podem ser melhores que a soma de seus componentes. Para usar um exemplo de Gestalt, uma melodia não é a soma de uma série de notas. O padrão das notas é o que conta. A melodia é a mesma e pode ter seu valor emergente em uma tecla e outra com um conjunto de notas totalmente diferente. Um jogador de basquete pode sacrificar [ênfase adicionada] seu próprio total de pontos por causa da equipe. Tudo o mais sendo igual, uma equipe que jogar como uma unidade vencerá [ênfase adicionada] aquela em que cada jogador individual focar exclusivamente seu próprio total de pontos. (Rachlin, 2012, pp. 12-13)

Outro exemplo pode ser delineado: um indivíduo se depara com uma criança sendo atacada por um cachorro e tenta salvar a criança em perigo. Ao fazer isso, ele próprio sai muito ferido da situação. Em outras ocasiões, esse mesmo indivíduo doa parte do seu salário para instituições de caridade; vê uma outra pessoa caindo nos trilhos do metrô e pula para ajudá-la a sair etc. Nessas circunstâncias, as ações altruístas envolvem consequências imediatas e potencialmente aversivas para o próprio indivíduo (e.g., ferimentos, perda de parte do salário, risco à própria vida). Contudo, essas ações fazem parte de um padrão comportamental amplo e complexo que está sendo reforçado no longo prazo. De acordo com Locey e Rachlin (2011), uma autoimagem altruísta, assim como ser visto como uma pessoa bondosa e generosa por outrem, poderia funcionar como um dos reforçadores responsáveis pela manutenção desse padrão. Nesse sentido, entender o altruísmo como um padrão molar de comportamento implica a possibilidade de aceitar que consequências reforçadoras positivas estariam mantendo o comportamento altruísta, mas elas estariam distendidas no tempo, reforçando o padrão como um todo e não as ações específicas que o compõem.

\section{Caracterização dos Componentes do Comportamento Altruísta}

As variáveis descritivas do comportamento altruísta identificadas nos artigos selecionados o definem preliminarmente como quaisquer ações ou padrão comportamental que sejam, em algum grau, custosas para o indivíduo que se comporta e que produzam benefícios ao(s) outro(s). Trata-se, então, de uma classe de ações, com diversas topografias, desde as mais simpáticas como, por exemplo, a doação (e.g., de moedas ou chocolate), a divisão de lucro, a devolução de pertences encontrados, 
a conservação de lugares públicos (e.g., não pichar), até topografias mais agressivas (e.g., eutanásia). Essa classe pode acontecer em diferentes situações antecedentes - envolvendo regras, autorregras (e.g., autoimagem) e operações estabelecedoras (e.g., empatia) - e consequentes (eventos reforçadores positivos e negativos). Os textos analisados consideram ainda que o enfrentamento de eventos aversivos por quem se comporta altruisticamente é parte das contingências envolvidas nesse comportamento.

Contudo, o que mantém o comportamento altruísta são as consequências reforçadoras. Nesse campo, diversas possibilidades foram levantadas. Alguns autores enfatizaram que as consequências mantenedoras desse comportamento são reforçadores imediatos, podendo ser reforçadores positivos (e.g., elogio, reconhecimento, valorização social) e/ou reforçadores negativos (e.g., esquiva de rejeição social, eliminação da condição aversiva de outrem). Outros argumentaram que são as consequências reforçadoras atrasadas que manteriam esse comportamento, caracterizando o altruísmo como um padrão comportamental molar e autocontrolado.

Tendo em vista as diversas variáveis consideradas pelos artigos selecionados, sobretudo no campo das consequências, algumas implicações podem ser levantadas. Em primeiro lugar, parece existir uma inconsistência entre a visão molar do comportamento altruísta e a possibilidade da manutenção desse comportamento por consequências reforçadoras imediatas positivas e negativas, pois o altruísmo, sendo entendido como um comportamento autocontrolado, requer a abdicação da possibilidade de reforçadores imediatos. Uma segunda implicação é que a defesa de que reforçadores mantêm o comportamento altruísta, sejam eles imediatos ou atrasados, possibilita a sua aproximação com o conceito de cooperação, que foi definido pelos textos analisados como um comportamento no qual há benefícios tanto para o indivíduo que se comporta quanto para outro(s) indivíduo(s) ${ }^{4}$ (Baker \& Rachlin, 2002).

Mais que uma aproximação, os conceitos de altruísmo e cooperação foram até mesmo sobrepostos parcialmente em alguns textos analisados. Chater et al. (2008) classificaram o altruísmo como uma forma de cooperação: "aparentemente, o comportamento cooperativo altruísta [ênfase adicionada] é tipicamente visto como intrigante de um ponto de vista normativo" (p. 403). Um comportamento poderia ser considerado como cooperativo altruísta quando o indivíduo que se comporta desse modo tem menos benefícios que o outro indivíduo da relação. De maneira semelhante, Rachlin (2019) considera que, ainda que existam benefícios para quem se comporta, quando a cooperação reduz os ganhos potenciais, ela pode ser considerada uma cooperação altruísta. Sendo assim, embora essa sobreposição parcial entre o altruísmo e a cooperação não tenha sido tratada explicitamente por todos os textos analisados (e.g., Grusec \& Redler, 1980; Parish, 1977; Peláez, 2001), partindo do conceito de cooperação e dos princípios analíticocomportamentais, alguns autores têm demonstrado que uma interpretação do altruísmo como um tipo de cooperação parece ser um dos caminhos possíveis (Suarez et al., 2018).

\section{Considerações Finais}

Esta pesquisa indica que é possível discutir o altruísmo de modo compatível com a Análise do Comportamento. O altruísmo pode ser estudado à luz do modelo selecionista (i.e., filogênese, ontogênese e cultura), mas é no nível ontogenético que as discussões analítico-comportamentais sobre o tema têm se concentrado. A análise descritiva apresentada buscou mostrar alguns componentes que caracterizam o comportamento altruísta na literatura consultada. No entanto, a multiplicidade de variáveis invocadas pelos estudos parece proporcionar também usos distintos do termo altruísmo, abrindo novos desafios para esse campo de pesquisa. Dessa forma, a sistematização das variáveis utilizadas no estudo do comportamento altruísta pode auxiliar a compreensão das especificidades desse comportamento, fomentando até mesmo questionamentos em relação à distinção e sobreposição entre o altruísmo e a cooperação.

Além disso, tendo em vista que este estudo teve como foco principal a conceituação e a explicação do altruísmo, novas pesquisas poderiam analisar sistematicamente os métodos que vêm sendo empregados no estudo desse comportamento, contribuindo para uma melhor compreensão de como este fenômeno está sendo investigado empiricamente na Análise do Comportamento. Revisões sistemáticas que contemplem teses e dissertações poderiam auxiliar igualmente nessa discussão. Outras pesquisas que investiguem análises de políticas públicas amparadas nos parâmetros descritos por esta pesquisa também poderiam contribuir para o debate. Variáveis como, por exemplo, (i) o custo de resposta, (ii) os tipos de reforçadores sociais envolvidos no altruísmo (e.g., elogios, "atribuições de caráter"), (iii) o comportamento verbal (e.g., as regras envolvidas no comportamento altruísta e a valoração do altruísmo como um comportamento "bom") poderiam ser investigados mais detalhadamente, fornecendo um suporte empírico para a discussão comportamental do altruísmo. Por fim, uma sistematização acerca do altruísmo pode servir de base para que outras pesquisas em Análise do Comportamento sejam realizadas, tendo a compreensão de que o fenômeno analisado pelos diversos métodos investigativos seja operacionalmente o mesmo.

4 Mesmo que existam diferentes definições de cooperação na literatura analítico-comportamental, os textos analisados que utilizaram esse conceito o fizeram subscrevendo essa definição. 


\section{REFERÊNCIAS}

Abib, J. A. D. (2016). Cenário de uma revolução psicológica. Revista Brasileira de Terapia Comportamental e Cognitiva, 18 (número especial), 27-39. https://doi.org/10.31505/rbtcc.v18i0.842

*Baker, F., \& Rachlin, H. (2002). Teaching and learning in a probabilistic prisoner's dilemma. Behavioural Processes, 57(23), 211-226. https://doi.org/10.1016/S0376-6357(02)00015-3

*Belisle, J., Dixon, M. R., \& Rowsey, K. E. (2019). The influence of contrived motivating operations on social discounting: Relative economic hardship affects choice. Journal of applied behavior analysis, 52(2), 408-421. https://doi.org/10.1002/jaba.540

*Bethlehem, D. W. (1973). Cooperation, competition and altruism among schoolchildren in Zambia. International Journal of Psychology, 8(2), 125-135. https://doi. org/10.1080/00207597308247069

*Brayko, C. A., Houmandar, R. A., \& Ghezzi, E. L. (2016). Organized cooperation: A behavioral perspective on volunteerism. Behavior and Social Issues, 25, 77-98. https:// doi.org/10.5210/bsi.v25i0.6739

*Chater, N., Vlaev, I., \& Grinberg, M. (2008). A new consequence of Simpson's paradox: Stable cooperation in one-shot prisoner's dilemma from populations of individualistic learners. Journal of Experimental Psychology: General, 137(3), 403-421. https:// doi.org/10.1037/0096-3445.137.3.403

Cialdini, R. B., Baumann, D. J., \& Kenrick, D. T. (1981). Insights from sadness: A three-step model of the development of altruism as hedonism. Developmental Review, 1(3), 207-223. https://doi.org/10.1016/0273-2297(81)90018-6

Dawkins, R. (1989). The selfish gene. Oxford University Press.

De Rose, J. C. (1982). Consciência e propósito no behaviorismo radical. In B. Prado Jr. (Ed.), Filosofia e comportamento (pp. 67-91). Brasiliense.

De Waal, F. (2010). A era da empatia: Lições da natureza para uma sociedade mais gentil. Companhia das Letras. (Trabalho original publicado em 2009)

Del Prette, A., \& Del Prette, Z. A. P. (2017). Competência social e habilidades sociais: Manual teórico-prático. Vozes.

Del Prette, Z. A. P., \& Del Prette, A. (2011). Psicologia das habilidades sociais na infância: Teoria e Prática. Vozes.

*Fantino, E., Gaitan, S., Kennelly, A., \& Stolarz-Fantino, S. (2007). How reinforcer type affects choice in economic games. Behavioural Processes, 75(2), 107-114. https://doi. org/10.1016/j.beproc.2007.02.001

Ferrari, J. R., Barone, R. C., Jason, L. A., \& Rose, T. (1985). The use of incentives to increase blood donations. The Journal of Social Psychology, 125(6), 791-793. https://doi.org/10.1080/ 00224545.1985.9713559

Fidelis, D. P., \& Faleiros, P. B. (2017). Dilema do prisioneiro na Análise do Comportamento: Uma revisão sistemática da literatura. Revista Brasileira de Análise do Comportamento, 13(1), 42-52. https://doi.org/10.18542/rebac.v13i1.5262

*Goldstein, R. S., Minkin, B. L., Minkin, N., \& Baer, D. M. (1978). Finders, keepers? An analysis and validation of a free-found-ad policy. Journal of Applied Behavior Analysis, 11(4), 465-473. https://doi.org/10.1901/jaba.1978.11-465

*Grusec, J. E., \& Redler, E. (1980). Attribution, reinforcement, and altruism: A developmental analysis. Developmental Psychology, 16(5), 525-534. https://doi.org/10.1037/00121649.16.5.525

Guerin, B. (2009). Análise do comportamento e a construção social do conhecimento. Revista Brasileira de Análise do Comportamento, 5(1), 117-137. https://doi.org/10.18542/ rebac.v5i1.726

Guimarães, R. K., \& Laurenti, C. (2019). O estudo do altruísmo na Análise do Comportamento: Um panorama a partir de uma revisão de literatura. Revista Brasileira de Terapia Comportamental e Cognitiva, 21(4), 487-502. https://doi. org/10.31505/rbtcc.v21i3.1305

Hamilton, W. D. (1963). The evolution of altruistic behavior. The American Naturalist, 97(896), 354-356. https://doi. org/10.1086/497114

Holpert, E. C. (2004). Questões sociais em Análise do Comportamento: Artigos do Behavior and Social Issues (1991-2000). Revista Brasileira de Terapia Comportamental e Cognitiva, 6(1), 1-16. https://doi.org/10.31505/rbtcc.v6i1.61

Israely, Y., \& Guttmann, J. (1983). Children's sharing behavior as a function of exposure to puppet-show and story models. The Journal of Genetic Psychology: Research and Theory on Human Development, 142(2), 311-312. https://doi.org/10.10 80/00221325.1983.10533522

*Killeen, P. R., \& Snowberry, K. (1982). Information and cooperative behavior. Behaviour Analysis Letters, 2(6), 353360. https://psycnet.apa.org/record/1983-22698-001

Laraway, S., Snycerski, S., Michael, J., \& Poling, A. (2003). Motivating operations and terms to describe them: Some further refinements. Journal of Applied Behavior Analysis, 36(3), 407414. https://doi.org/10.1901/jaba.2003.36-407

*Locey, M. L., \& Rachlin, H. (2013). Shaping behavioral patterns. Journal of the Experimental Analysis of Behavior, 99(3), 245259. https://doi.org/10.1002/jeab.22

Lopes, C. E., \& Laurenti, C. (2016). Metodologia da pesquisa conceitual em psicologia. In C. Laurenti, C. E. Lopes \& S. F. Araujo (Eds.), Pesquisa teórica em psicologia: Aspectos filosóficos e metodológicos (pp. 41-69). Hogrefe.

Maio, T. P., \& Silva, R. S. (2015). Comportamento governado por regras: Um estudo de revisão sistemática da literatura. Encontro: Revista de Psicologia, 15(22), 147-160. https://revista. pgsskroton.com/index.php/renc/article/view/2486

Martins, J. C., \& Leite, F. L. (2016). Metacontingências e macrocontingências: Revisão de pesquisas experimentais brasileiras. Acta Comportamentalia, 24(4), 453-469. http://www.revistas.unam.mx/index.php/acom/article/ view $/ 57977 / 51317$

Melo, C. M. (2004). A concepção de homem no behaviorismo radical de Skinner: Um compromisso com o 'bem'da cultura [Dissertação de mestrado, Universidade Federal de São Carlos]. Repositório Institucional UFSCar. https://repositorio.ufscar.br/ handle/ufscar/4877? show=full

Michael, J. (2000). Implications and refinements of the establishing operation concept. Journal of Applied Behavior Analysis, 33(4), 401-410. https://doi.org/10.1901/jaba.2000.33-401

Murta, S. G. (2005). Aplicações do treinamento em habilidades sociais: Análise da produção nacional. Psicologia: Reflexão e Crítica, 18(2), 283-291. https://doi.org/10.1590/S010279722005000200017

* Parish, T. S. (1977). The enhancement of altruistic behaviors in children through the implementation of language conditioning procedures. Behavior Modification, 1(3), 395-404. https://doi. org/10.1016/0146-6402(90)90002-8

*Peláez, M. (2001). Morality as a system of rule-governed behavior and empathy. Behavioral Development Bulletin, 1, 8-14. https:// doi.org/10.1037/h0100475

Rachlin, H. (1974). Self-control. Behaviorism, 2(1), 94-107. http:// www.jstor.org/stable/27758811

*Rachlin, H. (2012). Making IBM's computer, Watson, human. The Behavior Analyst, 35, 1-6. https://doi.org/10.1007/bf03392260

*Rachlin, H. (2019). Group selection in behavioral evolution. Behavioural Processes, 161, 65-72. https://doi.org/10.1016/j. beproc.2017.09.005 
*Rachlin, H., \& Locey, M. (2011). A behavioral analysis of altruism. Behavioural Processes, 87, 25-33. https://doi.org/10.1016/j. beproc. 2010.12 .004

Sampaio, A. A. S., \& Andery, M. A. P. A. (2010). Comportamento social, produção agregada e prática cultural: Uma análise comportamental de fenômenos sociais. Psicologia: Teoria e Pesquisa, 26(1), 183-192. http://www.scielo.br/pdf/ptp/v26n1/ a20v26n1

Skinner, B. F. (1965). Science and human behavior. The Free Press. (Trabalho original publicado em 1953).

Skinner, B. F. (1978). Reflections on behaviorism and society. Prentice-Hall.

Skinner, B. F. (1987). Upon further reflection. Prentice-Hall.

Skinner, B. F. (2002). Beyond freedom and dignity. Hackett Publishing Company. (Trabalho original publicado em 1971)

*Suarez, C. J., Villela, C. A. S. N., \& Benvenuti, M. F. L. (2018). Estudo experimental da cooperação na análise do comportamento: Buscando integrar aprendizagem, evolução e desenvolvimento. Revista Brasileira de Terapia Comportamental e Cognitiva, 20(4), 27-47. https://doi. org/10.31505/rbtcc.v20i4.1280

Vettorazzi, A., Frare, E., Souza, F. C., Queiroz, F. P., De Luca, G. G., Moskorz, L., \& Kubo, O. M. (2005). Avaliação de um programa para ensinar comportamento empático para crianças em contexto clínico. Interação em Psicologia, 2(9), 355-369. https://doi.org/10.5380/psi.v9i2.4780

*Watson, T. S. (1996). A prompt plus delayed contingency procedure for reducing bathroom graffiti. Journal of Applied Behavior Analysis, 29(1), 121-124. https://doi.org/10.1901/ jaba.1996.29-121

Wechsler, A. M., \& do Amaral, V. L. A. R. (2009). Correspondência verbal: Um panorama nacional e internacional das publicações. Temas em Psicologia, 17(2), 437-447. http://pepsic.bvsalud. org/pdf/tp/v17n2/v17n2a15.pdf

*Weiner, H. (1977). An operant analysis of human altruistic responding. Journal of the Experimental Analysis of Behavior, 27, 515-528. https://doi.org/10.1901/jeab.1977.27515

Zin, G. O. (2017). O comportamento altruísta no Jogo da Partilha Invertido [Dissertação de mestrado, Universidade Federal de São Carlos]. Repositório Institucional UFSCar. https:// repositorio.ufscar.br/handle/ufscar/9307

*Zin, G., Escobal, G., Esteves, G., \& Goyos, C. (2015). Sharing Game: Influence of gender, cost of response, history of reinforcement, and amount of money in the resource distribution of undergraduate students. Behavior Analysis: Research and Practice, 15(1), 65-80. https://doi.org/10.1037/ $\mathrm{h} 0101071$

* As referências analisadas na revisão estão indicadas com um asterisco (*). 